\title{
Usulan Perbaikan Postur Tubuh \& Perancangan Alat Material Handling untuk Petugas Pengantar Air Galon dengan Metode OWAS, REBA \& LI-NIOSH (Studi Kasus: PT Z - Depok, Meruyung)
}

\author{
Derdya Maharsayani ${ }^{1 *}$, Elty Sarvia ${ }^{2}$ \\ ${ }^{1,2}$ Program Studi Teknik Industri, Universitas Kristen Maranatha, Bandung, Indonesia \\ ('deamaharsayani@gmail.com)
}

\begin{abstract}
Abstrak - Kebutuhan jasa antar air galon di masa pandemi diperlukan agar konsumen tidak keluar rumah untuk membeli galon. PT $Z$ adalah distributor yang dapat mengantar galon hingga 200 air galon/hari. Petugas pengantar galon sering merasakan sakit badan, terlebih di tangan karena mengangkat galon secara manual. Tujuan penelitian ini adalah menganalisis keluhan sakit badan petugas, menganalisis tingkat risiko postur, dan merancang AMH untuk mengurangi tingkat risiko cedera postur tubuh. Pengumpulan data dilakukan dengan kuesioner Nordic Body Map, mengambil foto postur, serta mengukur dimensi bak truk. Selanjutnya, dilakukan analisis risiko postur berdasarkan persentase waktu kerja dengan metode OWAS (Ovako Work Analysis System), menganalisis tingkat risiko postur menggunakan sudut segmen tubuh dengan REBA (Rapid Entire Body Assessment), dan analisis LI (Lifting Index)-NIOSH untuk menghitung batas rekomendasi pengangkatan yang aman. Hasil OWAS ada 5 kegiatan dengan risiko tinggi, REBA ada 6 kegiatan dengan risiko sangat tinggi, dan LI-NIOSH 4 kegiatan seluruhnya berisiko cedera. Perlu ada tindakan perbaikan yaitu dengan merancang Alat Material Handling lift galon dan hand trolley, setelah dirancang Alat Material Handling dihitung kembali risiko postur tubuh dengan metode OWAS dan REBA agar dapat mengetahui penurunan tingkat risikonya. Didapatkan penurunan tingkat risiko hingga $38 \%$ untuk metode OWAS dan $52 \%$ untuk metode REBA.
\end{abstract}

Kata kunci: OWAS; postur tubuh; REBA; LI-NIOSH

\section{PENDAHULUAN}

Penanganan, pengangkatan, atau pengangkutan material secara manual merupakan penyebab terjadinya cedera non-fatal di antara karyawan di industri (Hemed \& Fatemeh, 2016). Kecelakaan kerja ini tentunya dapat menurunkan produktivitas. Pada saat ini masih banyak dilakukan penanganan material secara manual dengan membawa beban yang berat. Kegiatan manual material handling (MMH) jika tidak dilakukan dengan benar dan hati-hati berisiko besar menyebabkan cedera tulang belakang (low back pain), akibat pemindahan material secara manual yang cukup berat, posisi tubuh yang salah, pengulangan pekerjaan dan lingkungan. Jika dilakukan secara terus menerus akan berdampak buruk bagi kondisi kesehatan pekerja terutama dalam jangka panjang karena manusia memiliki batasan-batasan tertentu dalam penyelesaian suatu pekerjaan. (Deros, 2015).

Penelitian dilakukan terhadap petugas pengantar air galon PT. Z yang bertugas mengangkat galon ke rumah atau toko konsumen. Keluhan dari petugas pengantar galon adalah merasakan sakit di beberapa bagian tubuh terutama pada tangan dimana petugas harus mengangkat galon yang memiliki berat mencapai $19 \mathrm{~kg}$ dengan cara mengangkat dengan memegang bagian atas galon menggunakan tangan kanan dan mengangkat bagian bawah galon dengan menggunakan tangan kiri. Keluhan sakit badan tersebut disebabkan oleh beban kerja petugas yang cukup berat yaitu menurunkan galon dari atas truk sejumlah 200 air galon setiap harinya secara manual tanpa alat bantu. Penerapan ergonomi merupakan suatu keharusan di setiap tempat kerja sehingga rasa tidak nyaman maupun keluhan pekerja dapat diminimalisir (Tarwaka., 2004). Dari permasalahan tersebut dapat diidentifikasi masalahnya yaitu petugas pengantar air galon merasakan sakit pada bagian tubuh tertentu terutama pada tangan karena harus mengangkat 200 air galon setiap hari secara manual, postur tubuh pengangkatan air galon yang dilakukan oleh petugas berisiko cedera, dan perlunya alat bantu untuk petugas air galon agar dapat mengurangi risiko cedera. Dengan demikian tujuan dari penelitian ini adalah menganalisis keluhan sakit badan Musculoskeletal Disorders (MSDs) yang dirasakan petugas angkat air galon saat ini. menganalisis tingkat risiko postur kerja petugas angkat air galon aktual ditinjau dengan analisis metode OWAS (Ovako Work Posture Analysis System), REBA (Rapid Entire Body Assessment) dan LI-NIOSH (Lifting IndexNational Institute of Occupational Safety dand Health). Jika belum baik, maka akan diusulkan alat material handling untuk membantu pekerja dalam melakukan pekerjaannya agar bisa meminimasi tingkat risiko cedera, serta menganalisis penurunan tingkat risiko cedera dari metode OWAS dan REBA setelah mengusulkan alat material handling (AMH). Metode ergonomis, seperti OWAS dan REBA, telah dikembangkan terutama untuk 
menilai faktor fisik atau yang berhubungan dengan pekerjaan, dan bukan untuk mengevaluasi psikososial/organisasi dan faktor individu. (Kee, 2021). Metode REBA terutama digunakan untuk analisis postur yang tidak wajar dan tidak untuk evaluasi gerakan berulang (Hita-Guti'errez, 2020). Alat ini telah digunakan dalam studi yang melibatkan postur mengangkat, dan penggunaannya telah dipelajari untuk menentukan keuntungan dan kerugian dari teknik observasi untuk menilai beban postural (Kee dan Karwowski, 2007). Salah satu manfaat utama metoda REBA adalah memungkinkan untuk varians sehubungan dengan postur netral. Selain itu, REBA mengambil dinamika kinerja menjadi pertimbangan selama evaluasi (Kjellberg et al., 2000). NIOSH mengusulkan penilaian aman atau tidaknya suatu aktivitas pengangkatan didasarkan pada Lifting Index (LI). LI dirumuskan sebagai perbandingan antara batas beban yang direkomendasikan untuk diangkat terhadap beban yang seharusnya diangkat (Iridiastadi, 2014).

\section{STUDI LITERATUR}

Menurut International Ergonomics Association (IEA), "Ergonomi (atau disebut human factor) adalah disiplin ilmu yang berkaitan dengan pemahaman interaksi antara manusia dan elemen sistem lainnya, dan metode untuk merancang untuk mengoptimalkan kesejahteraan manusia dan kinerja sistem secara keseluruhan.

Sistem Penilaian Postur Kerja Ovako (OWAS) - dirancang untuk mengidentifikasi frekuensi dan durasi postur selama tugas tertentu, dan tindakan korektif (Gomez-Galan, 2017; Karhu, 1977) Penilaian Risiko REBA (Rapid Entire Body Assessment) memungkinkan untuk identifikasi gangguan muskuloskeletal yang diderita oleh pekerja di berbagai bidang, terutama postur yang tidak wajar (forced posture). REBA telah dikembangkan dan dapat digunakan untuk penilaian beban kerja dengan materi manual menangani tugas. (Hignett \& Mcatamney, 2000). REBA memperhatikan dinamika kinerja dalam pertimbangan selama evaluasi dilakukan (Kjellberg, 2000). RWL (Recommended Weight Limit) berfungsi untuk merekomendasikan batas beban yang boleh diangkat oleh pekerja tanpa menimbulkan cedera musculoskeletal untuk berbagai kondisi pengangkatan (Waters, 1993). Bagaimana melakukan analisis terhadap hasil perhitungan LI-NIOSH mengusulkan penilaian aman atau tidaknya suatu aktivitas pengangkatan didasarkan pada Lifting Index (LI). LI dirumuskan sebagai perbandingan antara batas beban yang direkomendasikan untuk diangkat terhadap beban yang seharusnya diangkat. Rekomendasi yang diberikan adalah : apabila $\mathrm{LI} \leq 1$, maka perkejaan tersebut aman; apabila $1<\mathrm{LI} \leq 3$, maka pekerjaan tersebut mungkin berisiko; dan apabila LI $\geq 3$ maka pekerjaan tersebut berisiko (Iridiastadi, 2014).

\section{METODOLOGI}

Proses pengumpulan data, pertama dilakukan observasi dan wawancara data umum petugas air galon, lalu dikumpulkan juga kuesioner Nordic Body Map untuk mendapatkan data keluhan sakit badan petugas. Pengumpulan foto postur tubuh aktual terhadap 14 tahapan kegiatan pengangkatan air galon yang dibagi menjadi pengambilan dari bak truk rak level 1 dan rak level 2, untuk data sudut pengangkatan air galon dari truk sebagai inputan metode REBA. Setelah itu mengukur data pengangkatan untuk metode LI serta mengukur bak truk untuk usulan alat material handling. Setelah mengumpulkan data NBM akan dinilai tingkat risiko cedera petugas angkat air galon, jika tingkat risiko nya tinggi maka akan dilanjutkan ke pengolahan data OWAS, REBA dan LI-NIOSH. Pengolahan data dengan metode OWAS, REBA dan LI-NIOSH akan dilakukan secara paralel. Perbedaan yang paling signifikan dari metode OWAS, REBA dan LI adalah pada metode OWAS dilakukan pengukuran tubuh dengan aktivitas yang dibagi per satuan persen waktu, pada metode REBA dilakukan analisis risiko postur tubuh dengan sudut derajat pergerakan tubuh. Lalu pada metode LI-NIOSH dihitung dulu RWL dengan memperhitungkan frekuensi kegiatan dan jarak pengangkatan air galon. Kemudian dilanjutkan dengan perhitungan LI dengan cara membagi bobot beban actual dengan min dari (RWL awal, RWl akhir). Hasil dari skor sikap kerja metode OWAS, REBA dan LI-NIOSH akan dibandingkan dan digabungkan sebagai pembuktian posisi tubuh pekerja harus diperbaiki segera.

Selanjutnya untuk usulan dari penelitian berikut adalah merancang alat material handling yang dapat membantu pekerjaan petugas untuk menurunkan air galon dari truk tanpa risiko cedera. Lalu melakukan perhitungan perbandingan metode OWAS dan REBA postur tubuh usulan menggunakan alat material handling, untuk dapat mengetahui persentase penurunan tingkat risiko cedera antara postur tubuh aktual dengan usulan. Pada usulan tidak menghitung metode RWL dan LI kembali dikarenakan pada postur usulan, 
operator sudah menggunakan alat material handling, yang dimana petugas tidak perlu lagi mengangkat galon secara manual melainkan hanya perlu menggeser galon.

\section{HASIL DAN DISKUSI}

\section{A. Nordic Body Map}

Hasil skor Nordic Body Map yang didapat setelah diisi oleh petugas pengantar air galon adalah 72 yang menunjukkan bahwa tingkat risiko. Batas yang direkomendasi maximum skor 70 yang diklasifikasikan tingkat risiko sedang dan maximum skor 49 untuk risiko rendah (Tarwaka, 2015). Kegiatan yang dilakukan petugas termasuk klasifikasi skor tingkat risiko tinggi sehingga diperlukan tindakan perbaikan postur tubuh segera, skor tersebut karena petugas harus mengangkat air galon ke rumah atau toko konsumen setiap harinya dengan total galon 200. Bagian tubuh yang terasa sangat sakit diantaranya adalah bagian tubuh bahu kiri, bokong, siku kiri, lengan bawah kanan, tangan kiri, paha kanan, dan betis kanan.

\section{B. Analisis Gabungan dari Metode OWAS, REBA dan RWL}

Berikut adalah tabel rangkuman hasil nilai akhir dari metode OWAS, REBA dan LI-NIOSH:

Tabel 1

Rangkuman Metoda OWAS, REBA dan LI-NIOSH

\begin{tabular}{|c|c|c|c|c|c|c|c|c|c|c|c|c|c|c|}
\hline \multirow{2}{*}{$\begin{array}{c}\text { No. Elemen } \\
\text { Kegiatan }\end{array}$} & \multicolumn{3}{|c|}{ Elemen Kegiatan } & \multirow[b]{2}{*}{ NBM } & \multirow{2}{*}{$\begin{array}{l}\text { Kesimpulan } \\
\text { NBM }\end{array}$} & \multirow{2}{*}{$\begin{array}{l}\text { Nilai Akhir } \\
\text { OWAS }\end{array}$} & \multirow{2}{*}{ Kesimpulan OWAS } & \multirow{2}{*}{$\begin{array}{c}\text { No. Elemen } \\
\text { Kegiatan }\end{array}$} & \multirow{2}{*}{\begin{tabular}{|l|} 
Posisi \\
Tubuh \\
\end{tabular}} & \multirow{2}{*}{$\begin{array}{l}\text { Nilai Akhir } \\
\text { REBA }\end{array}$} & \multirow{2}{*}{ Kesimpulan REBA } & \multirow{2}{*}{$\begin{array}{l}\text { Nilai Akhir LI } \\
\text { Terpilith }\end{array}$} & \multirow{2}{*}{\begin{tabular}{|c|} 
Kesimpulan \\
LI
\end{tabular}} & \multirow{2}{*}{$\begin{array}{c}\begin{array}{c}\text { Kesimpulan } \\
\text { Akhir }\end{array} \\
\end{array}$} \\
\hline & Kegiatan & Keterangan & Rak Level & & & & & & & & & & & \\
\hline 1 & Menjangkau air galon dari bak & \multirow{6}{*}{$\begin{array}{r}\text { Mengambil } \\
\text { Galon dari } \\
\text { Pinggir Truk }\end{array}$} & \multirow{14}{*}{ 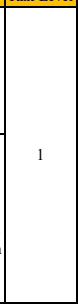 } & \multirow{28}{*}{$\begin{array}{c}72 \text { (Keluhan } \\
\text { sangat sakit } \\
\text { pada bagana } \\
\text { tubuhl bahu } \\
\text { kiri, bokong, } \\
\text { siku kiri, } \\
\text { lengan } \\
\text { bawah } \\
\text { kanan, } \\
\text { tangan kiri, } \\
\text { paha kanan } \\
\text { dan betis } \\
\text { kanan) }\end{array}$} & \multirow{28}{*}{$\begin{array}{c}\text { Diperlukan } \\
\text { tindakan } \\
\text { perbaikan } \\
\text { segera }\end{array}$} & 1 & Aman & 1 & Kanan & 3 & Harus ada tindakan perbaikan segera & \multirow{6}{*}{3,262} & \multirow{6}{*}{$\begin{array}{c}\text { Beresiko } \\
\text { Cedera }\end{array}$} & \multirow{29}{*}{\begin{tabular}{|c} 
NBM: ada \\
keluhan, \\
OWAS: \\
beresko, \\
REBA: \\
beresiko, LI \\
beresiko. = \\
Perluadanya \\
perbaikan \\
dengan \\
perancangan
\end{tabular}} \\
\hline & truk & & & & & & Allant & & \begin{tabular}{|l|} 
Kiri \\
\end{tabular} & 2 & $\begin{array}{l}\text { Perlu ada tindakan } \\
\end{array}$ & & & \\
\hline & Mengangkat air galon berjalan & & & & & & & & Kanan & 2 & Perlu ada tindakan & & & \\
\hline 2 & $\begin{array}{c}\text { ke rumah konsumen } \\
\end{array}$ & & & & & 1 & Aman & 2 & \begin{tabular}{|c|} 
Kiri \\
\end{tabular} & 2 & Perlu ada tindakan & & & \\
\hline 3 & Menurunkan air galon ke & & & & & 3 & Diperlukan tindakan dalam & 3 & Kanan & 3 & Harus ada tindakan perbaikan segera & & & \\
\hline & & & & & & & waktu dekat & 3 & \begin{tabular}{|l|} 
Kiri \\
\end{tabular} & 4 & Harus ada tindakan sekarang & & & \\
\hline & & \multirow{8}{*}{$\begin{array}{c}\text { Mengambil } \\
\text { Galon dari } \\
\text { nn } \\
\text { Truk Bagian } \\
\text { Lebih Dalam }\end{array}$} & & & & & Diperlukan perbaikan & & Kanan & 3 & Harus ada tindakan perbaikan segera & \multirow{8}{*}{5,183} & \multirow{8}{*}{$\begin{array}{c}\text { Beresiko } \\
\text { Cedera }\end{array}$} & \\
\hline 4 & ada di tengah bak truk & & & & & 2 & beberapa waktu kedepan & 4 & Kiri & 3 & Harus ada tindakan perbaikan segera & & & \\
\hline 5 & Menarik air galon ke pinggir & & & & & & Diperlukan perbaikan & 5 & Kanan & 3 & Harus ada tindakan perbaikan segera & & & \\
\hline & truk & & & & & 2 & beberapa waktu kedepan & 3 & Kiri & 2 & $\begin{array}{l}\text { Perlu ada tindakan } \\
\end{array}$ & & & \\
\hline & Mengangkat air galon berjalan & & & & & & & & Kanan & 2 & Perlu ada tindakan & & & \\
\hline 6 & ke rumah konsumen & & & & & 1 & Aman & 6 & \begin{tabular}{|l|} 
Kiri \\
\end{tabular} & 2 & $\begin{array}{l}\text { Perlu ada tindakan } \\
\end{array}$ & & & \\
\hline 7 & Menurunkan air galon ke & & & & & & Diperlukan tindakan dalam & & Kanan & 3 & Harus ada tindakan perbaikan segera & & & \\
\hline & lantai & & & & & 3 & waktu dekat & 7 & \begin{tabular}{|l|} 
Kiri \\
\end{tabular} & 4 & Harus ada tindakan sekarang & & & \\
\hline & Menjangkau air galon dari bak & \multirow{6}{*}{$\begin{array}{r}\text { Mengambil } \\
\text { Galon dari } \\
\text { Pinggir Truk }\end{array}$} & \multirow{15}{*}{2} & & & & & & Kanan & 2 & $\begin{array}{l}\text { Perlu ada tindakan } \\
\end{array}$ & & & \\
\hline 8 & truk & & & & & 1 & Aman & 8 & \begin{tabular}{|l|} 
Kiri \\
\end{tabular} & 2 & Perlu ada tindakan & & & \\
\hline 9 & Mengangkat air galon berjalan & & & & & & Diperlukan perbaikan & 9 & Kanan & 3 & Harus ada tindakan perbaikan segera & & Beresiko & \\
\hline 9 & ke rumah konsumen & & & & & 2 & beberapa waktu kedepan & 9 & \begin{tabular}{|l|} 
Kiri \\
\end{tabular} & 3 & Harus ada tindakan perbaikan segera & 3,506 & Cedera & \\
\hline 10 & Menurunkan air galon ke & & & & & 3 & Diperlukan tindakan dalam & & Kanan & 3 & Harus ada tindakan perbaikan segera & & & \\
\hline 10 & lantai & & & & & & waktu dekat & 10 & Kiri & 4 & Harus ada tindakan sekarang & & & \\
\hline 11 & & \multirow{8}{*}{$\begin{array}{c}\text { Mengambil } \\
\text { Galon dari } \\
\text { Truk Bagian } \\
\text { Lebih Dalam }\end{array}$} & & & & & Diperlukan tindakan dalam & & Kanan & 4 & Harus ada tindakan sekarang & & & \\
\hline 11 & ada di tengah bak truk & & & & & 3 & waktu dekat & 11 & \begin{tabular}{|l|} 
Kiri \\
\end{tabular} & 4 & Harus ada tindakan sekarang & & & \\
\hline & Menarik air galon ke pinggir & & & & & & Diperlukan perbaikan & & Kanan & 2 & Perlu ada tindakan & & & \\
\hline 12 & truk & & & & & 2 & beberapa waktu kedepan & 12 & \begin{tabular}{|c|} 
Kiri \\
\end{tabular} & 2 & Perlu ada tindakan & 6665 & Beresiko & \\
\hline & & & & & & & & & Kanan & 3 & Harus ada tindakan perbaikan segera & 6,603 & Cedera & \\
\hline 13 & ke rumah konsumen & & & & & 2 & beberapa waktu kedepan & 13 & \begin{tabular}{|c|} 
Kiri \\
\end{tabular} & 3 & Harus ada tindakan perbaikan segera & & & \\
\hline & Menurunkan air galon ke & & & & & & Diperlukan tindakan dalam & & Kanan & 3 & Harus ada tindakan perbaikan segera & & & \\
\hline 14 & lantai & & & & & 3 & waktu dekat & 14 & \begin{tabular}{|c|} 
Kiri \\
\end{tabular} & 4 & Harus ada tindakan sekarang & & & \\
\hline & Rata-1 & $\frac{1}{1-\text { rata Nilai Akhi }}$ & & & & & 2,071 & & & & 2,857 & & & \\
\hline
\end{tabular}

Pada tabel rangkuman diatas, terlihat rata-rata nilai akhir dari 14 kegiatan yang dianalisis memiliki skor yang cukup tinggi. Pada metode OWAS rata-rata nilai adalah $2,071 \approx 2$ dengan tingkat risiko 2 yang artinya diperlukan perbaikan beberapa waktu kedepan (Tarwaka, 2011). Pada metode REBA rata-rata nilainya adalah $2,857 \approx 3$ yang memiliki arti harus ada tindakan perbaikan segera (Hignett \& Mcatamney, 2000). Pada metode LI-NIOSH dengan rata-rata LI 4,654 > 3 yang artinya kegiatan berisiko cedera (Iridiastadi, 2014). Postur tubuh petugas pada saat ini berisiko cedera sehingga dibutuhkan tindakan perbaikan segera, dengan demikian perlu adanya tindakan perbaikan teknis yaitu dengan merancang produk alat material handling untuk memperbaiki kegiatan postur tubuh yang risiko nya tinggi, membantu pekerjaan petugas angkat air galon dan meminimasi risiko kerja yang dapat terjadi.

\section{Usulan Perancangan Alat Material Handling}

Lift galon berfungsi sebagai alat untuk membantu menurunkan galon dari atas truk ke lantai, lift ini terletak di sisi kiri bak truk galon. Lift berikut memakai tenaga listrik motor yang disambungkan ke aki truk dimana ada konverter pengubah daya dari DC ke AC untuk dapat menyalakan lift galon, lalu pada saat proses penggunaan lift galon mesin truk harus dinyalakan agar truk tidak kehabisan listrik. Pada satu kali beroperasi naik turun nya lift dapat mengangkat sampai 2 galon sehingga dapat mempersingkat waktu petugas dalam 
proses pengangkatan galon ke rumah atau toko konsumen. Terdapat remote tombol untuk mengoperasikan lift, yaitu tombol bulat merah untuk menaikan dan menurunkan lift sesuai dengan tinggi yang diinginkan. Tombol hitam atas untuk menaikan lift sampai tinggi maksimum ke atas bak truk level 2, dan tombol hitam bawah berfungsi untuk menurunkan lift sampai tinggi minimum lift ke arah lantai
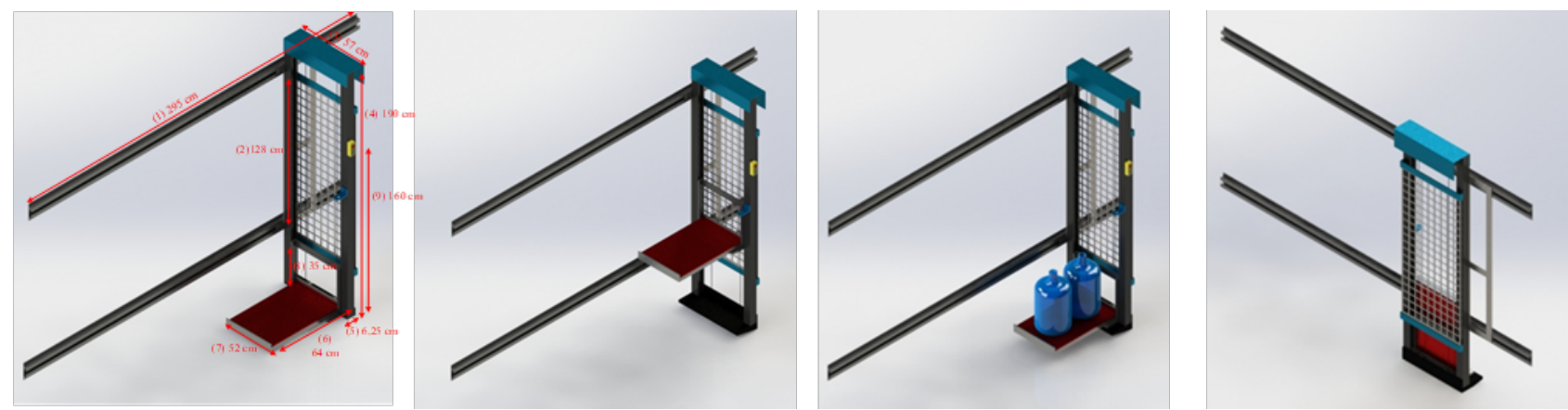

Gambar 1. Lift Galon
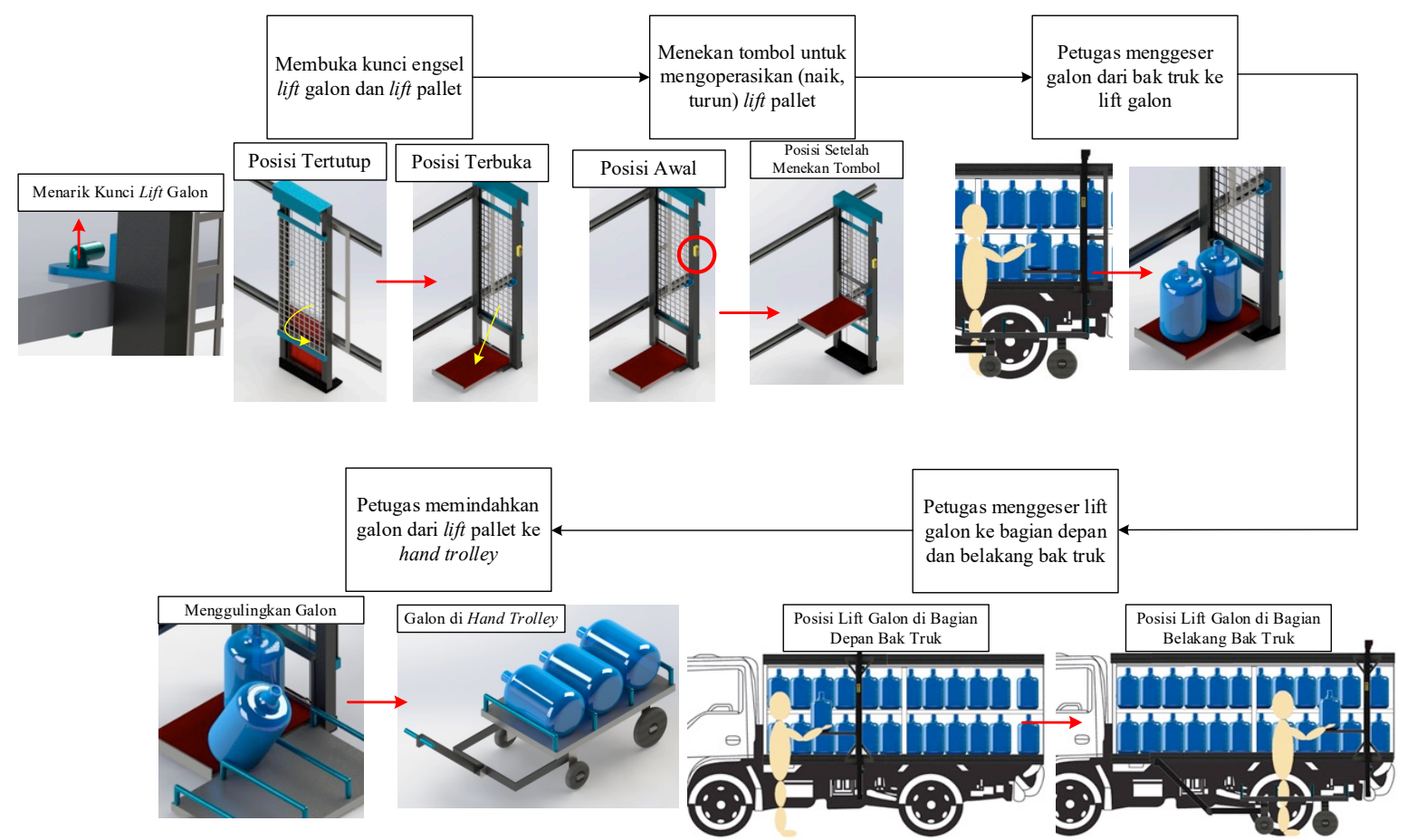

Gambar 2. Mekanisme Penggunaan Lift Galon

Tujuan dirancang hand trolley sebagai berikut adalah untuk memudahkan proses pemindahan galon dari truk ke rumah atau toko konsumen. Pembuatan hand trolley berikut ukurannya sudah disesuaikan dengan data anthropometri dan ukuran truk serta lift galon yang telah dirancang.

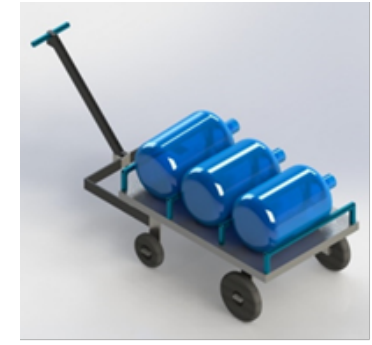

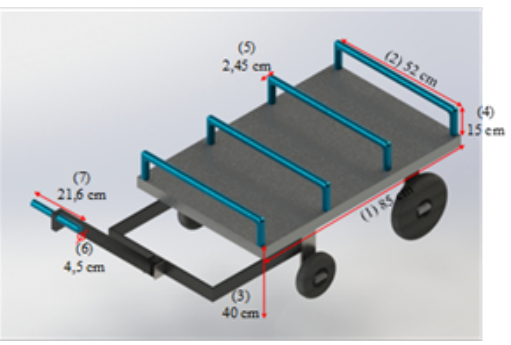

Gambar 3. Hand Trolley
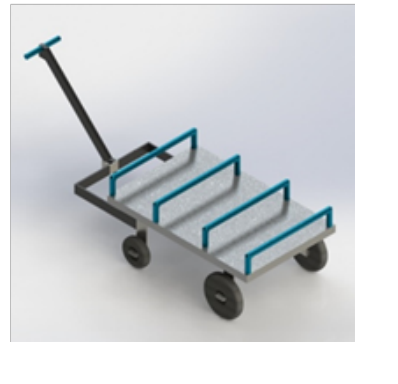
Produk alternatif pengangkat galon manual yaitu gagang galon berikut ini sudah ada di pasaran. Produk tersebut dipertimbangkan untuk menjadi alat bantu mengangkat galon petugas pengantar galon karena alat berikut mudah untuk digunakan serta mudah untuk disimpan.

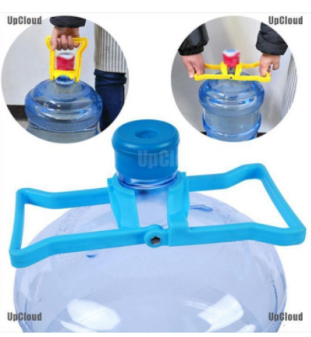

(https://www.tokopedia.com/visastores/handle-pembawa-galon-air-hemat-energi-model-tebal-0y?whid=0)

Gambar 4. Gagang Galon

\section{Usulan Postur Kerja Petugas Angkat Air Galon dengan Alat Material Handling Menggunakan Metode OWAS dan REBA}

Setelah merancang 2 usulan alat material handling untuk membantu petugas mengangkat dan membawa air galon dari truk ke rumah, maka perlu diuji lagi ke perhitungan metode OWAS dan REBA untuk membuktikan apakah dengan menggunakan alat material handling lift galon dan rancangan hand trolley, perbandingan skor dari metode OWAS dan REBA bisa turun dan dapat mengurangi risiko cedera. Berikut adalah perbandingan siklus pengangkatan untuk postur aktual dan usulan.

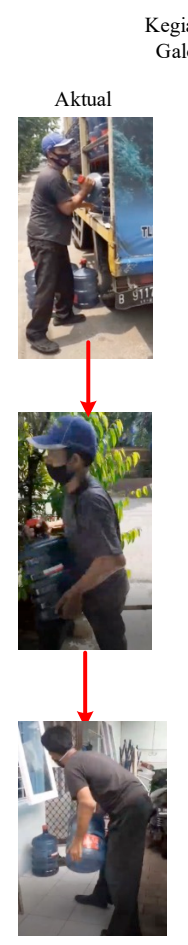

Kegiatan Mengangkat Air
Galon dari Rak Level 1

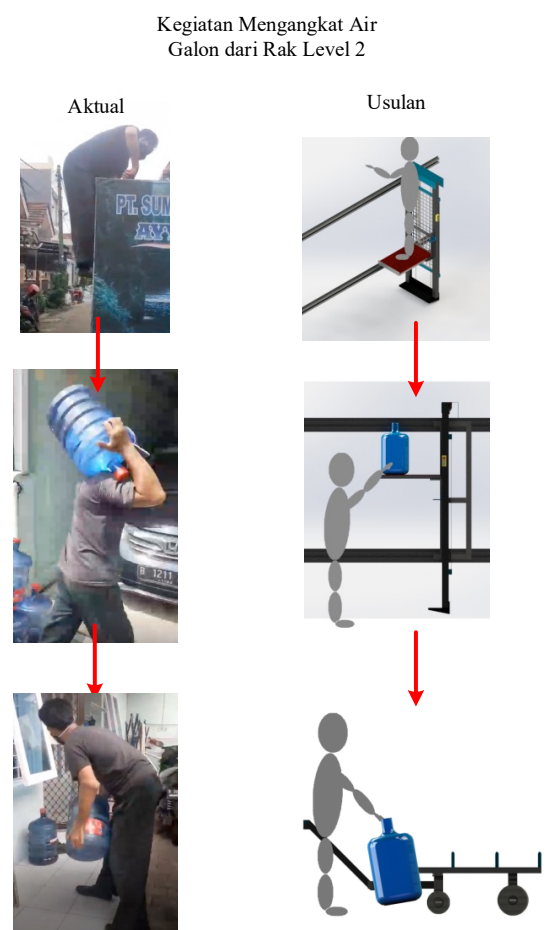

Gambar 5. Siklus Mengangkat Galon

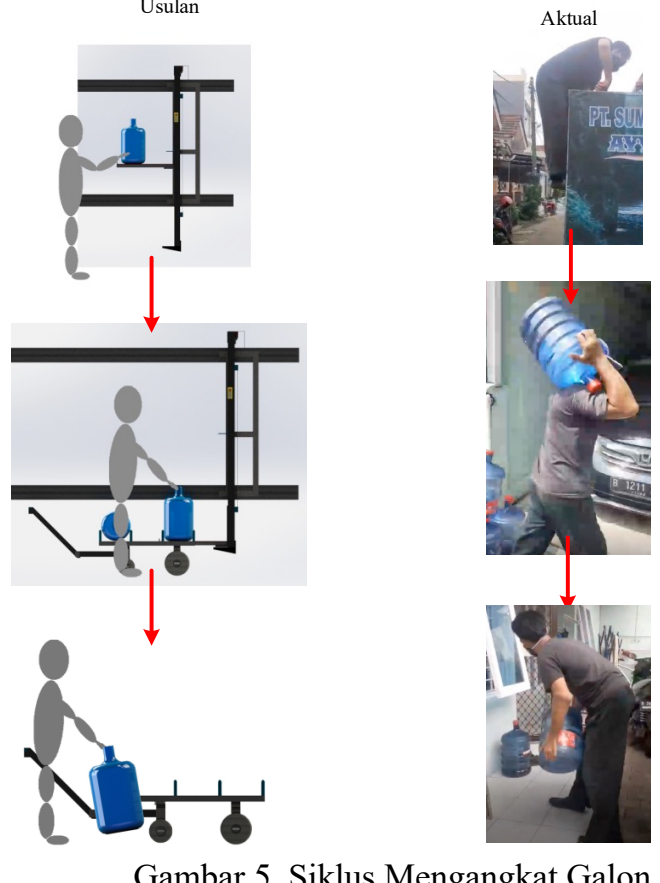

Siklus pengangkatan galon dari rak level $1 \mathrm{di}$ atas terlihat perbedaan pada postur aktual petugas dengan postur usulan, yaitu pada postur aktual petugas harus menarik dan mengangkat galon dari truk, sedangkan postur usulan petugas hanya perlu menggeser galon dari bak truk ke lift galon. Lalu pada kegiatan postur aktual kedua petugas harus mengangkat dan membawa berjalan ke lantai rumah sedangkan pada postur usulan petugas hanya perlu menggeser galon dari lift galon ke hand trolley lalu menarik hand trolley ke rumah atau toko. Lalu pada postur aktual petugas harus menurunkan membungkuk ke lantai, sedangkan pada postur usulan jarak vertikal hand trolley ke lantai yang cukup pendek yaitu $40 \mathrm{~cm}$ membuat petugas tidak perlu terlalu membungkuk untuk menaruh ke lantai. 
Siklus pengangkatan galon dari rak level 2 di atas terlihat perbedaan pada postur aktual petugas dengan postur usulan, yaitu pada postur aktual petugas harus memanjat truk untuk menjangkau truk, sedangkan postur usulan petugas dapat naik ke atas lift untuk menjangkau galon sehingga lebih aman. Selanjutnya pada kegiatan postur aktual, petugas harus mengangkat dan membawa galon diatas bahu lalu berjalan ke lantai rumah, sedangkan pada postur usulan petugas hanya perlu menggeser galon dari rak truk level 2 ke lift galon, setelah itu lift akan menurunkan galon sejajar dengan hand trolley agar petugas tinggal menggulingkan galon ke hand trolley. Lalu pada postur aktual petugas harus menurunkan membungkuk ke lantai, sedangkan pada postur usulan jarak vertikal hand trolley ke lantai yang cukup pendek yaitu $40 \mathrm{~cm}$ membuat petugas tidak perlu terlalu membungkuk untuk menaruh ke lantai

- Perhitungan Metode OWAS

Berikut adalah tabel rangkuman perbandingan perhitungan Metode OWAS aktual dengan perhitungan Metode OWAS usulan.

Tabel 2

Rangkuman Perbandingan Metode OWAS Aktual dan Usulan

\begin{tabular}{|c|c|c|c|c|c|c|c|}
\hline \multirow{3}{*}{$\begin{array}{c}\text { No. Elemen } \\
\text { Kegiatan }\end{array}$} & \multirow{2}{*}{\multicolumn{3}{|c|}{ Elemen Kegiatan }} & \multicolumn{2}{|r|}{ Aktual } & \multicolumn{2}{|r|}{ Usulan } \\
\hline & & & & Nilai Akhir & & Nilai Akhir & \\
\hline & Kegiatan & Keterangan & Rak Level & OWAS & & OWAS & \\
\hline 1 & Menjangkau air galon dari bak truk & Mengambil & \multirow{7}{*}{ 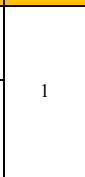 } & 1 & Aman & 1 & Aman \\
\hline 2 & Mengangkat air galon berjalan ke rumah konsumen & Galon dari & & 1 & Aman & - & - \\
\hline 3 & Menurunkan air galon ke lantai & Pinggir Truk & & 3 & Diperlukan tindakan dalam waktu dekat & 2 & \begin{tabular}{|l} 
Diperlukan perbaikan beberapa waktu kedepan \\
\end{tabular} \\
\hline 4 & Menjangkau air galon yang ada di tengah bak truk & \multirow{4}{*}{$\begin{array}{c}\text { Mengambil } \\
\text { Galon dari } \\
\text { Truk Bagian } \\
\text { Lebih Dalam }\end{array}$} & & 2 & Diperlukan perbaikan beberapa waktu kedepan & 1 & Aman \\
\hline 5 & Menarik air galon ke pinggir truk & & & 2 & Diperlukan perbaikan beberapa waktu kedepan & 1 & Aman \\
\hline 6 & \begin{tabular}{|l|} 
Mengangkat air galon berjalan ke rumah konsumen \\
\end{tabular} & & & 1 & Aman & - & - \\
\hline 7 & Menurunkan air galon ke lantai & & & 3 & Diperlukan tindakan dalam waktu dekat & 2 & Diperlukan perbaikan beberapa waktu kedepan \\
\hline 8 & Menjangkau air galon dari bak truk & \multirow{3}{*}{$\begin{array}{c}\text { Mengambil } \\
\text { Galon dari } \\
\text { Pinggir Truk }\end{array}$} & \multirow{7}{*}{2} & 1 & Aman & 1 & Aman \\
\hline 9 & Mengangkat air galon berjalan ke rumah konsumen & & & 2 & Diperlukan perbaikan beberapa waktu kedepan & - & - \\
\hline 10 & Menurunkan air galon ke lantai & & & 3 & Diperlukan tindakan dalam waktu dekat & 2 & Diperlukan perbaikan beberapa waktu kedepan \\
\hline 11 & Menjangkau air galon yang ada di tengah bak truk & \multirow{4}{*}{$\begin{array}{c}\text { Mengambil } \\
\text { Galon dari } \\
\text { Truk Bagian } \\
\text { Lebih Dalam }\end{array}$} & & 3 & Diperlukan tindakan dalam waktu dekat & 1 & Aman \\
\hline 12 & Menarik air galon ke pinggir truk & & & 2 & Diperlukan perbaikan beberapa waktu kedepan & 1 & Aman \\
\hline 13 & Mengangkat air galon berjalan ke rumah konsumen & & & 2 & Diperlukan perbaikan beberapa waktu kedepan & - & - \\
\hline 14 & Menurunkan air galon ke lantai & & & 3 & Diperlukan tindakan dalam waktu dekat & 2 & Diperlukan perbaikan beberapa waktu kedepan \\
\hline
\end{tabular}

- Perhitungan Metode REBA

Berikut adalah tabel rangkuman perbandingan perhitungan Metode REBA aktual dengan perhitungan Metode REBA usulan.

Tabel 3

Rangkuman Perbandingan Metode REBA Aktual dan Usulan

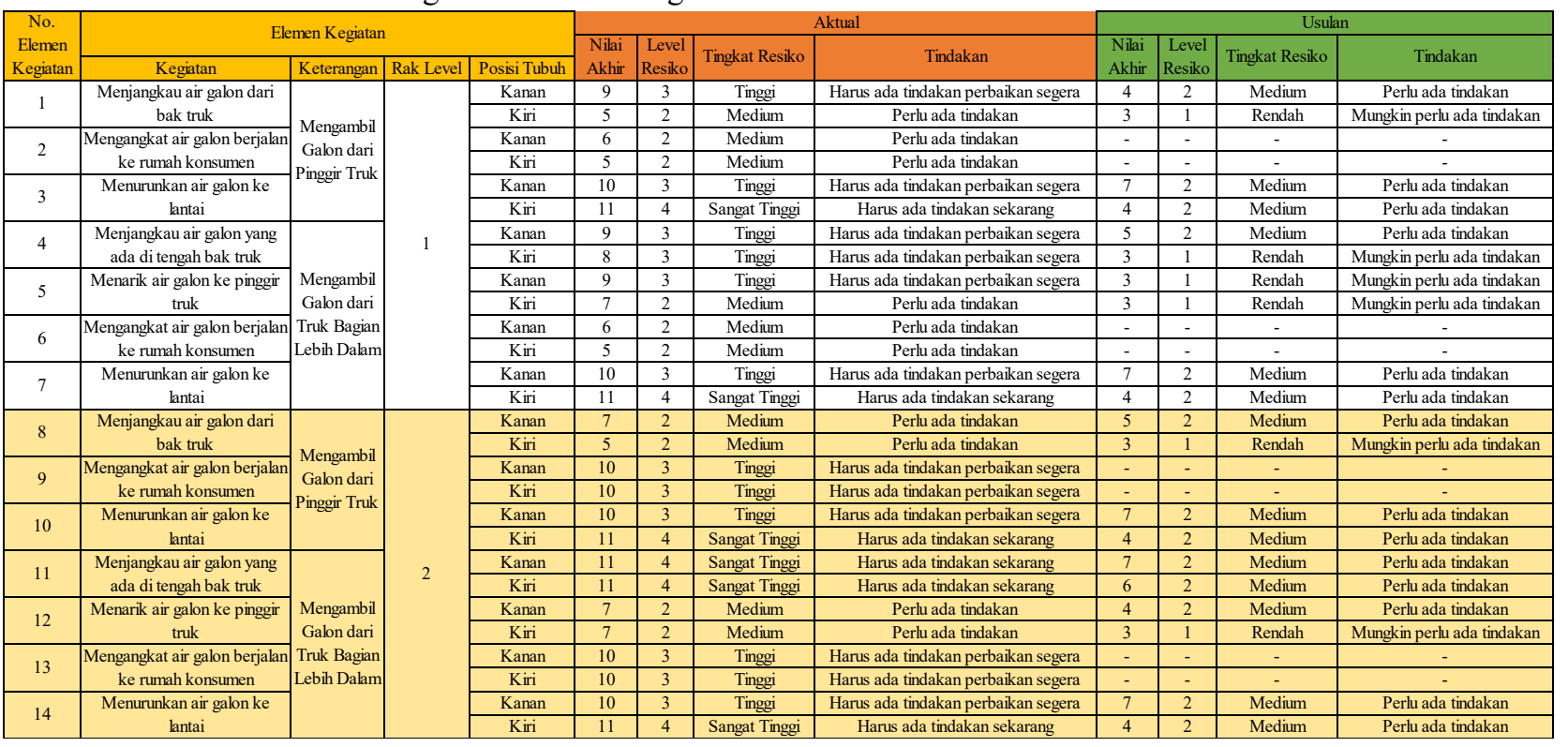

- Perbandingan Metode OWAS dan REBA Usulan

Berdasarkan tabel rangkuman perbandingan nilai akhir metode OWAS dan REBA aktual dengan usulan, terlihat dari perbandingan rata-rata nilai akhir metode OWAS kegiatan postur tubuh aktual dan usulan 
mengalami penurunan nilai sebanyak 32\%. Lalu pada nilai akhir metode REBA untuk postur kegiatan aktual dan usulan mengalami penurunan nilai sebanyak $52 \%$.

Tabel 4

Rangkuman Perbandingan Metode OWAS dan REBA Usulan

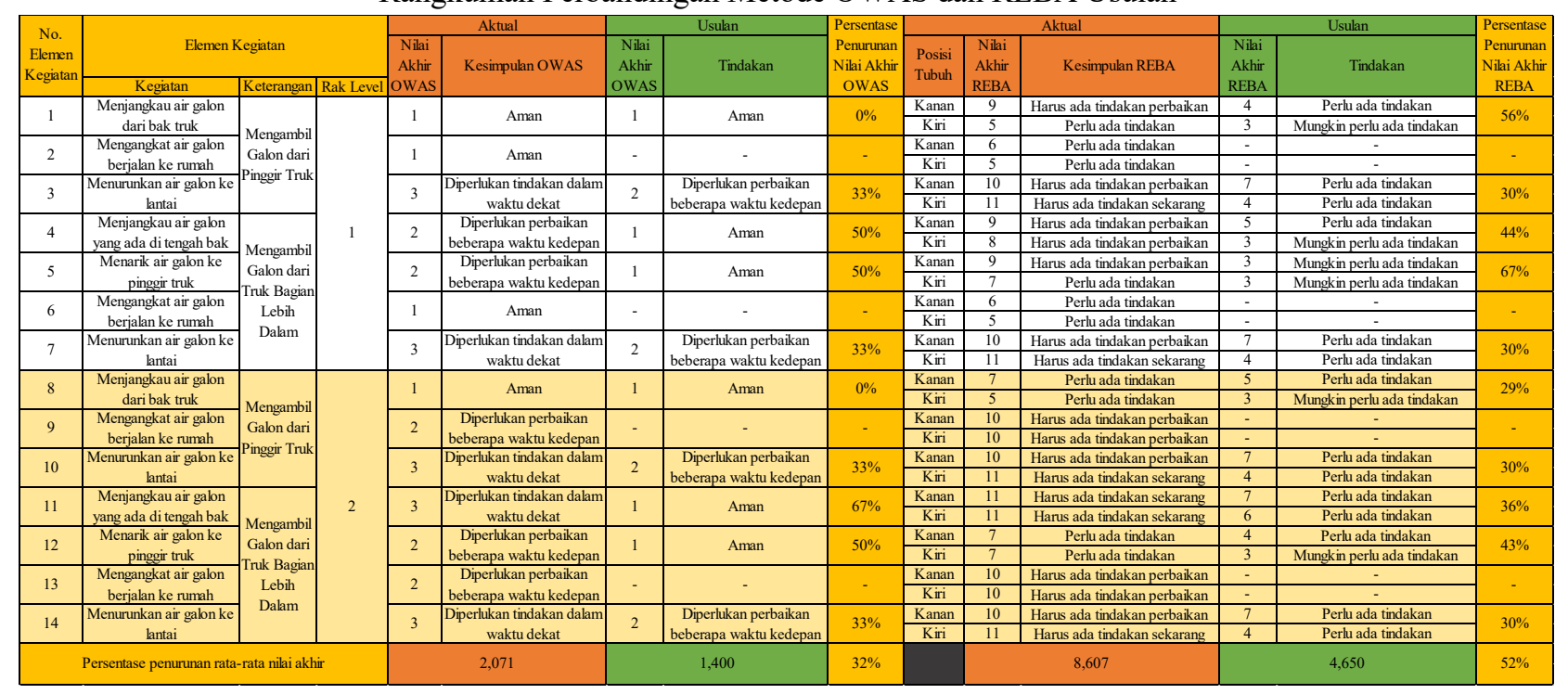

\section{KESIMPULAN}

Berdasarkan hasil pengolahan data menggunakan kuesioner Nordic Body Map dianalisis beberapa bagian tubuh yang dirasakan sangat sakit oleh petugas yaitu pada bahu kiri, bokong, siku kiri, lengan bawah kanan dan tangan kiri, paha kanan dan betis kanan. Rasa sakit tersebut dikarenakan postur tubuh pengangkatan yang tidak baik, dan frekuensi pengangkatan yang banyak yaitu 200 galon/hari. Hasil pengolahan data tingkat risiko postur tubuh aktual pekerja untuk metode OWAS dari 14 kegiatan yang diamati ada 5 kegiatan dengen level risiko 3 (tinggi), hasil analisis metode REBA dari 28 kegiatan (bagian tubuh kanan dan kiri) yang diamati ada 6 kegiatan dengan level risiko 4 (sangat tinggi), dan hasil analisis metode LI-NIOSH dari 4 kegiatan yang diamati seluruhnya memiliki nilai Lifting Index (LI) yang lebih besar dari 3 sehingga berisiko cedera. Dengan tingkat risiko cedera yang tinggi tersebut maka perlu diusulkan alat material handling yaitu lift galon dan hand trolley untuk memperbaiki postur tubuh pekerja beserta mengurangi tingkat risiko dan beban angkat galon yang harus dibawa oleh petugas agar petugas tidak merasakan sakit lagi pada bagian tubuh tertentu. Setelah melakukan perancangan alat material handling maka dihitung kembali postur tubuh usulan menggunakan metode OWAS dan REBA. Perbandingan hasil metode OWAS postur tubuh aktual dengan usulan menunjukkan ada penurunan tingkat risiko sebanyak 38\% dan metode REBA 52\%. Dengan demikian usulan alat material handling tersebut dapat menyelesaikan masalah rasa sakit petugas dengan menurunkan nilai akhir tingkat risiko metode OWAS mencapai 38\% dan dengan metode REBA hingga 52\%.

\section{DAFTAR PUSTAKA}

Deros, B. M. (2015). A Study on Ergonomics Awareness among Workers Performing Manual Material Handling Activities. . Procedia Social and Behavioral Scinces, 195, 1666 - 1673; https://doi.org/10.1016/j.sbspro.2015.06.238.

Gomez-Galan, M. P.-A.-F.-M. ( (2017)). Musculoskeletal disorders: OWAS review. Ind. Health 55(4), , 314 337.

Hemed Nadri, Fasih-Ramandi Fatemeh. (2016). Assessment of manual material handling in a tile and ceramic factory using the National Institute for Occupational Safety and Health equation in 2016. Journal of Occupational Health and Epidemiology 5(2):, 105-111; 10.18869/acadpub.johe.5.2.105. 
Hignett, S., \& Mcatamney, L. (2000). Rapid entire body assessment (REBA). Appl. Ergon. Applied Ergonomics, 201-205.

Hita-Guti'errez, M. G.-G.-P.-F. (2020). An Overview of REBA Method Applications in the World . Int. J. Environ. Res. Public Health 2020, 17, 2635, doi:10.3390/ijerph17082635.

International Ergonomics Association,. (2021). What is Ergonomics? accessed on 3 april 2020, pp. https://iea.cc/what-is ergonomics/.

Iridiastadi, H. \& Yassierli (2014). Ergonomi Suatu Pengantar. Bandung: PT.Remaja Rosdakarya.

Karhu, O. K. (1977). Correcting working postures in industry: a practical method for analysis. Appl. Ergon. 8(4), 199-201.

Kee, D. (2021). Comparison of OWAS, RULA and REBA for assessing potential work-related musculoskeletal disorders. International Journal of Industrial Ergonomics 83, https://doi.org/10.1016/j.ergon.2021.103140.

Kjellberg K., J. C. (2000). An observation instrument for assessment of work technique in patient transfer tasks. Applied Ergonomics, 31(2), 139-150; DOI: 10.1016/s0003-6870(99)00046-0.

Tarwaka. (2011). Dasar-Dasar Pengetahuan Ergonomi dan Aplikasi di Tempat Kerja. Edisi 1 Cetakan 2 . Surakarta : Harapan Press.

Tarwaka. (2015). Ergonomi Indutri: Dasar-Dasar Ergonomi dan Implementasi di Tempat Kerja. Surakarta: Harapan Press Edisi: I I- Cetakan: 1.

Tarwaka., S. S. (2004). Ergonomi untuk Keselamatan, Kesehatan Kerja dan Produktivitas. Surakarta Ed. 1, Cet. 1.: UNIBA Press.

Waters, T. P.-A. (1993). Revised NIOSH equation for the design and evaluation of manual lifting tasks. Ergonomics, 36(7), 749-776.

https://www.tokopedia.com/visastores/handle-pembawa-galon-air-hemat-energi-model-tebal-0y?whid=0.

(n.d.). Handle pembawa air galon. 